\title{
RESEARCH
}

Open Access

\section{Development of novel EST microsatellite markers for genetic diversity analysis and correlation analysis of velvet antler growth characteristics in Sika deer}

Boyin Jia', Guiwu Wang², Junjun Zheng ${ }^{2}$, Wanyun Yang ${ }^{2}$, Shuzhuo Chang ${ }^{2}$, Jiali Zhang ${ }^{1}$, Yuan Liu', Qining Li', Chenxia Ge ${ }^{3}$, Guang Chen ${ }^{4}$, Dongdong Liu ${ }^{4,5^{*}}$ (D) and Fuhe Yang ${ }^{2 *}$

\begin{abstract}
Background: Sika deer is one of the most popular and valued animals in China. However, few studies have been conducted on the microsatellite of Sika deer, which has hampered the progress of genetic selection breeding. To develop and characterize a set of microsatellites for Sika deer which provide helpful information for protection of Sika deer natural resources and effectively increase the yield and quantity of velvet antler.

Results: We conducted a transcriptome survey of Sika deer using next-generation sequencing technology. One hundred eighty-two thousand two hundred ninety-five microsatellite markers were identified in the transcriptome, 170 of 200 loci were successfully amplified across panels of 140 individuals from Shuangyang Sika deer population. And 29 loci were found to be obvious polymorphic. Number of alleles is from 3 to 14. The expected heterozygosity ranged from 0.3087 to 0.7644 . The observed heterozygosity ranged from 0 to 0.7698 . The polymorphism information content values of those microsatellites varied ranged from 0.2602 to 0.7507 . The marker-trait association was tested for 6 important and kernel characteristics of two-branched velvet antler in Shuangyang Sika deer through one-way analysis of variance. The results showed that marker-trait associations were identified with 8 different markers, especially M009 and M027.
\end{abstract}

Conclusions: This study not only provided a large scale of microsatellites which were valuable for future genetic mapping and trait association in Sika deer, but also offers available information for molecular breeding in Sika deer.

Keywords: EST microsatellite markers, Genetic diversity, Sika deer, Transcriptome, Velvet antler

\footnotetext{
*Correspondence: liudongdong@jlau.edu.cn; yangfh@126.com

${ }^{4}$ Key laboratory of Straw Biology and Utilization, The Ministry of Education, Jilin Agricultural University, 2888 Xincheng Street, Changchun 130118, China ${ }^{2}$ Institute of Wild Economic Animals and Plants and State Key Laboratory for Molecular Biology of Special Economical Animals, Chinese Academy of Agricultural Sciences, 4899 Juye Street, Changchun 130112, China

Full list of author information is available at the end of the article
}

(c) The Author(s). 2020 Open Access This article is licensed under a Creative Commons Attribution 4.0 International License, which permits use, sharing, adaptation, distribution and reproduction in any medium or format, as long as you give appropriate credit to the original author(s) and the source, provide a link to the Creative Commons licence, and indicate if changes were made. The images or other third party material in this article are included in the article's Creative Commons licence, unless indicated otherwise in a credit line to the material. If material is not included in the article's Creative Commons licence and your intended use is not permitted by statutory regulation or exceeds the permitted use, you will need to obtain permission directly from the copyright holder. To view a copy of this licence, visit http://creativecommons.org/licenses/by/4.0/ The Creative Commons Public Domain Dedication waiver (http://creativecommons.org/publicdomain/zero/1.0/) applies to the data made available in this article, unless otherwise stated in a credit line to the data. 


\section{Background}

Molecular markers are commonly used to test the genetic characteristics of species within or among populations [1]. These molecular markers mainly include microsatellite, single nucleotide polymorphisms (SNPs), random amplified polymorphic DNA (RAPD), amplified fragment length polymorphisms (AFLPs), sequencerelated amplified polymorphisms (SRAPs) and so on [2]. Microsatellite markers are tandem repeats of 1-6 bp, usually associated with copy slippage and DNA repair, and are distributed in the genome of all organisms [3]. Microsatellite markers are characterized by high polymorphism, high information content, specificity, dominance, and reproducibility [4]. They can be classified into genomic microsatellite and expressed sequence tag microsatellite (EST microsatellite) based on their locations [5]. EST microsatellite was found in selectively more constrained regions of the genome [6]. Although compared with genomic microsatellite, EST microsatellite has some disadvantages: (1) The polymorphism level of EST microsatellite was lower than that of genomic microsatellite; (2) Due to a consequence of the undetected presence of introns in flanking regions, the amplicon size may be different from expected [7]. However, this was balanced by the following advantages over genomic microsatellite: (1) EST microsatellite was used to detect the variation in the expressed portion of the genome, which may give the concerned marker-trait associations; (2) EST microsatellite could be developed at no cost from the EST databases which become a fast, efficient and low-cost choice; (3) Unlike genomic microsatellite, once developed, EST microsatellite may be highly conserved among a number of related species, resulting in a high level of transferability $[6,8]$.

Due to the lack of available genomic information, it is difficult to develop ideal microsatellite. Transcriptome sequencing is an alternative to whole-genome sequencing for obtaining microsatellite, which are essential for developing abundant EST microsatellite and identifying target genomic regions for important characteristics [9]. In the last decade, deep transcriptome sequencing has been generated in model and non-model organisms, which have greatly accelerated the collection of genetic resources and the understanding of the interest of gene expression, regulation and networks [10-12]. Because on these advantages, transcriptome sequencing has been widely used in non-model animals for EST microsatellite development, including the Siberian tiger, the ridgetail white prawn Exopalaemon carinicauda, the Yellow catfish and so on [13-15].

Sika deer is one of the most popular and valued animals in China [16]. The velvet antler has long been a traditional tonic or alternative medicine, according to ancient Chinese pharmaceutical monographs [17]. It is also a useful model for the study of the mechanisms of organ regeneration, rapid growth and mineralization in mammals [18]. At present, the key problem of raising economic benefits of deer breeding is to improve the yield and quality of velvet antler in China. The growth characteristics of velvet antler are closely related to genetic factors. Despite substantial age- and environmentrelated variation, velvet antler size was also heritable [19]. Conventional breeding cycles are long, and it is difficult to make early selection. The research on the velvet antler growth characteristics by using molecular genetic markers can effectively overcome the shortcomings of traditional methods and improve the velvet antler yield of Sika deer. Due to the lack of sufficient molecular markers, Sika deer breeding technology is relatively backward. Although $\mathrm{Zu}$ et al. (2001) developed 200 microsatellite markers in Sika deer, most microsatellite markers were borrowed from cattle and the polymorphism was relatively low [20]. Until recently, 22,479 microsatellite markers were obtained from $125 \mathrm{M}$ bp genomic data of Sika deer by using IlluminaHiSeq 2500 sequencing technology. Among them, 29 microsatellite markers were identified to be polymorphic, of which 10 loci could be used for paternity testing of Sika deer [21]. So far, only genomic microsatellite markers have been developed and EST microsatellite markers have not been reported. In addition, microsatellite markers have been mainly applied to genetic diversity, genetic structure analysis and paternity testing in Sika deer [22-24]. Only a few microsatellite markers related to the production performance of the velvet antler have been reported. $\mathrm{Li}$ et al. (2011) found that BE, CE genotype at BM1225 and AA genotype at T172 could be regarded as linkage genetic marker of velvet antler weight of Xingkaihu Sika deer [25]. Yang et al. (2014) found that the second exon C629G of melatonin receptor 1A gene showed significant association with velvet antler yield, and the velvet antler weight of CC genotype was higher than that of GC genotype in Wusan Sika deer [26]. However, complex characteristics could not be completely controlled by a single gene, and it required a series of genes.

To solve this problem, through Illumina sequencing and bioinformatics analysis, approximately 289 gigabytes (289G) high-quality reads were obtained and were assembled into $1,348,618$ unigenes. In our study, the frequency and distribution of 182,295 potential EST microsatellite markers in the Sika deer transcriptome were analyzed. Two hundred EST microsatellite markers loci which expressed in antler were selected for primer design, of these, 170 loci were successfully amplified across panels of 140 individuals from Shuangyang Sika deer population. And 29 loci were found to be obvious polymorphic. Finally, the marker-trait association was tested for important and kernel characteristics of velvet 
antler in Shuangyang Sika deer. We found 8 EST microsatellites, especially M009 and M027, which can be used as molecular markers in the breeding process of weight of the two-branched velvet antler. The development of tremendous Sika deer molecular markers could help to protect germplasm resources. At the same time, it can effectively increase the yield and quantity of velvet antler. The present study thus represents the first comprehensive application of transcriptome sequencing in the development of Sika deer EST microsatellite markers.

\section{Results}

\section{Characterization of EST microsatellites in the Sika deer Transcriptome}

A total of 1,348,618 unigenes covering $0.74 \mathrm{~GB}$ and 182 , 295 EST microsatellite loci were identified from 182,295 sequences of unigenes. The average density of EST microsatellite was $9.53 \mathrm{~kb}$. In total, 22,261 unigenes (12.21\%) contained more than one EST microsatellite loci.

We analyzed the distribution of EST microsatellite that has $1-6$ bp repeat motif. The mono-nucleotide was the most common type of repeat $(70.15 \%)$, followed by dinucleotide and tri-nucleotide $(21.54,7.4 \%)$, thirdly tetranucleotide, penta-nucleotide and hexa-nucleotide was only $0.91 \%$ of total EST microsatellite. In addition, the highest number of repeat motifs per locus was 11-36 (82, $042,45.01 \%)$. This was followed by $10(47,829,26.24 \%), 6$ (23,194, 12.72\%), 5 (10,764, 5.9\%), 7 (10,132, 5.56\%), 8 $(4952,2.72 \%)$ and $9(3382,1.86 \%)$ repeats (Table 1$)$.

After the removal of the mono-nucleotide motifs, the di-nucleotide motifs were the main type in transcriptome of Sika deer $(39,258,72.15 \%)$ (Additional file 1). Among the di-nucleotide motifs, the most dominant type was AC/GT (26,522, 67.56\%) (Fig. 1a). Two most frequent repeats in the tri-nucleotide were AGC/CTG (3420, 25.36\%) and CCG/CGG (3296, 24.44\%) (Fig. 1b). Among the tetra-nucleotide motifs, AATG/ATTC (250, 15.60\%) was the most dominant motif (Fig. 1c).

In this study, the length of less than $12 \mathrm{bp}$ microsatellite was removed. The total number of EST microsatellites screened from Sika deer was 72,316 (ranging in length from $12 \mathrm{bp}$ to $313 \mathrm{bp}$ ). Among them, the lengths of 56,632 EST microsatellites (90.76\%) were $12-20 \mathrm{bp}$, and the lengths of 6684 EST microsatellites (9.24\%) were longer than $20 \mathrm{bp}$.

\section{Genetic diversity analysis}

To verify the identified microsatellite markers, 18,692 primer pairs, which removed the length of less than $12 \mathrm{bp}$ and the mono-nucleotide duplication microsatellites, were designed from 58,503 microsatellites expressed in velvet antler. Then, a total of 200 EST microsatellites of velvet antler were selected for validation. In this study, TP-M13 microsatellite PCR method was used to screen for primer. One hundred seventy of two hundred primer pairs successfully PCR-amplified, producing products of the expected size. Of the 170 primer pairs, 29 pairs showed polymorphisms among 140 shuangyang Sika deer samples $\left(\mathrm{N}_{\mathrm{a}} \geq 2\right)$. In total, 153 alleles were detected across the collected individuals, with the number of alleles per locus varying from 3 to 14 . The average $\mathrm{N}_{\mathrm{a}}$ was 5.6 and the average $\mathrm{N}_{\mathrm{e}}$ was 2.6. The number of $\mathrm{N}_{\mathrm{a}}$ of microsatellite M082 and M027 were 14 and 12 respectively. The number of $\mathrm{N}_{\mathrm{e}}$ of microsatellite M005, M084, M099, M121, M131 and M132 were the least, all of which were 3 (Table 2).

Among the 29 EST microsatellite loci, the $\mathrm{H}_{e}$ varied from 0.3087 to 0.7644 , with an average of $0.6018 \pm 0.1190$, while the $\mathrm{H}_{\mathrm{o}}$ varied from 0 to 0.7698 , with an average of $0.5127 \pm 0.2010$. The PIC values ranged from 0.2602 to 0.7507 , with an average of $0.5450 \pm 0.1262$ (Table 2). These 29 microsatellites exhibited medium and high levels of PIC (PIC > 0.25). The effective candidate microsatellite markers developed in this study would greatly promote the genetic diversity studies of varieties in Sika deer.

\section{Analysis of correlation between EST microsatellite and velvet antler characteristics}

Characteristics of the model and coefficients that resulted from the multiple linear regressions were detailed in Table 3. The model suggested that main beam circle, main beam length, mouth circle, first tine circle, mouth

Table 1 Frequency of different repeat motifs among the EST microsatellite of Sika deer

\begin{tabular}{lllllllll}
\hline Repeats & Mo & $\mathrm{Di}$ & Tri & Tetra & Penta & Hexa & Total & Percentage (\%) \\
\hline 5 & - & - & 9244 & 1472 & 47 & 1 & 10,764 & 5.9 \\
6 & - & 19,632 & 3438 & 118 & 5 & 1 & 23,194 & 12.72 \\
7 & - & 9367 & 759 & 5 & 1 & 0 & 10,132 & 5.56 \\
8 & - & 4904 & 42 & 4 & 1 & 1 & 4952 & 2.72 \\
9 & - & 3375 & 3 & 1 & 2 & 1 & 3382 & 1.86 \\
10 & 46,133 & 1696 & 0 & 0 & 0 & 0 & 47,829 & 26.24 \\
$11-36$ & 81,754 & 284 & 0 & 3 & 0 & 1 & 82,042 & 45.01 \\
Total & 127,887 & 39,258 & 13,486 & 1603 & 56 & 5 & 182,295 & 100 \\
Percentage (\%) & 70.15 & 21.54 & 7.4 & 0.88 & 0.03 & $2.74 \mathrm{E}-03$ & 100 & - \\
\hline
\end{tabular}




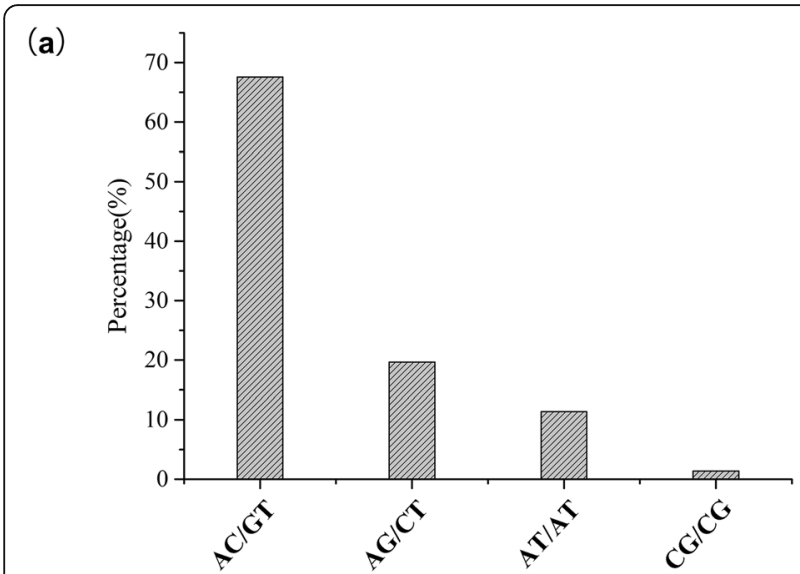

(c)

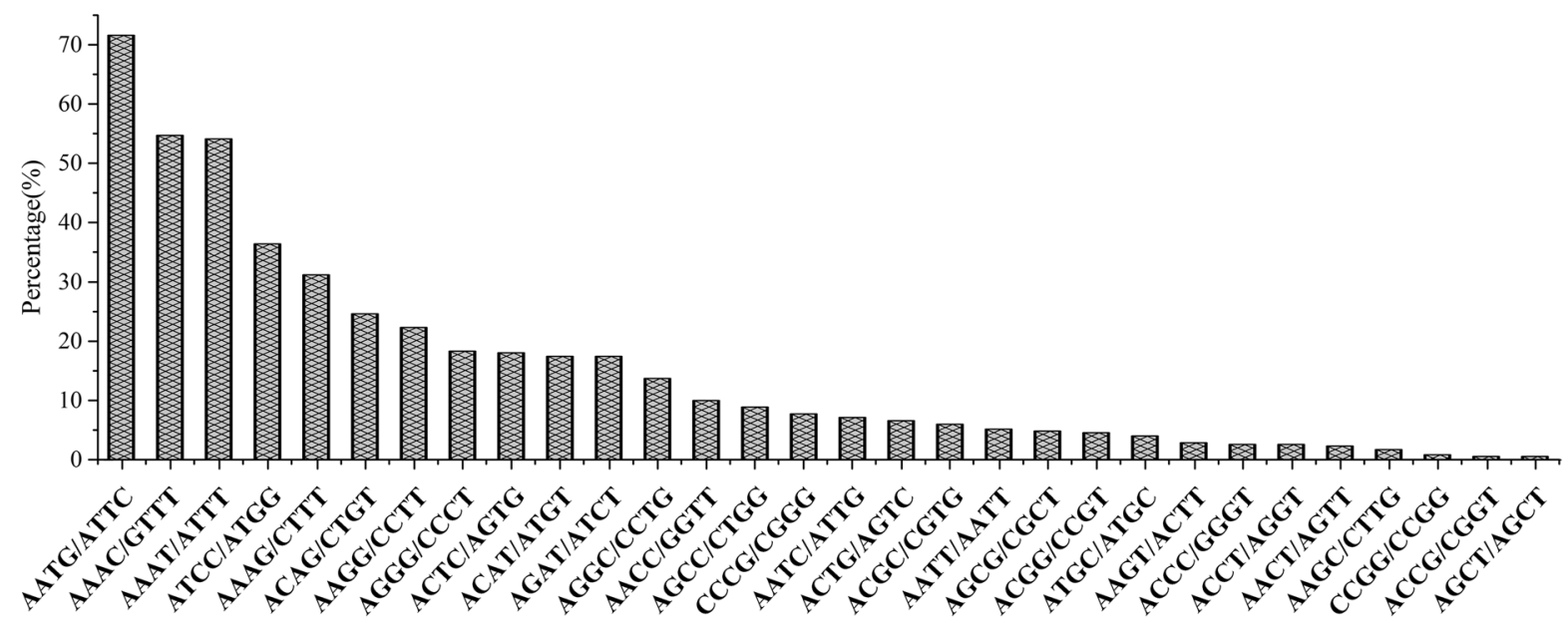

Fig. 1 Frequency of different repeat motifs among the microsatellite markers of Sika deer was determined by transcriptome sequencing. a dinucleotide repeats. $\mathbf{b}$ tri-nucleotide repeats. $\mathbf{c}$ tetra-nucleotide repeats

length explain $86.9 \%$ of the normalized velvet antler weight $\left(R^{2}=0.869\right)$. Main beam circle $(\beta=0.071, P<$ $0.001)$, main beam length $(B=0.027, P<0.001)$, mouth circle $(\beta=0.043, P<0.001)$, mouth length $(\beta=0.016, P<$ $0.05)$, first tine circle $(\beta=0.019, P<0.05)$ were positively correlated with velvet antler weight. The correlation between EST microsatellite markers and the above growth characteristics of velvet antler of Shuangyang Sika deer was analyzed by one-way analysis of variance. The results showed that 8 EST microsatellite loci (M001, M009, M027, M084, M093, M113, M136, and M159) were significantly correlated with the above characteristics (Table 4).

Of particular concern was M009, which screened 9 genotypes of Sika deer (Fig. 2). Among them, genotype $357 / 363$ had the highest mean value of velvet antler weight and main beam length. On the contrary, genotype $361 / 361$ had the lowest mean values of velvet antler weight and main beam length (Table 5, Fig. 3a, b). The correlation between M009 alleles and velvet antler traits (b)

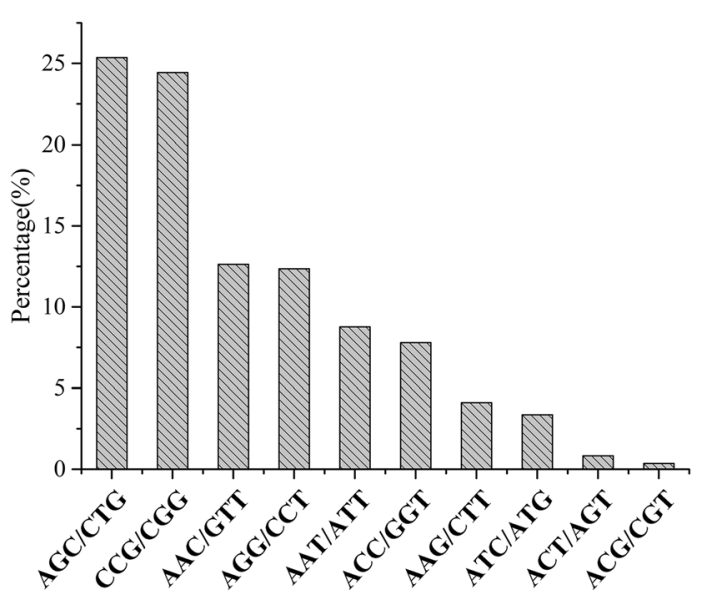




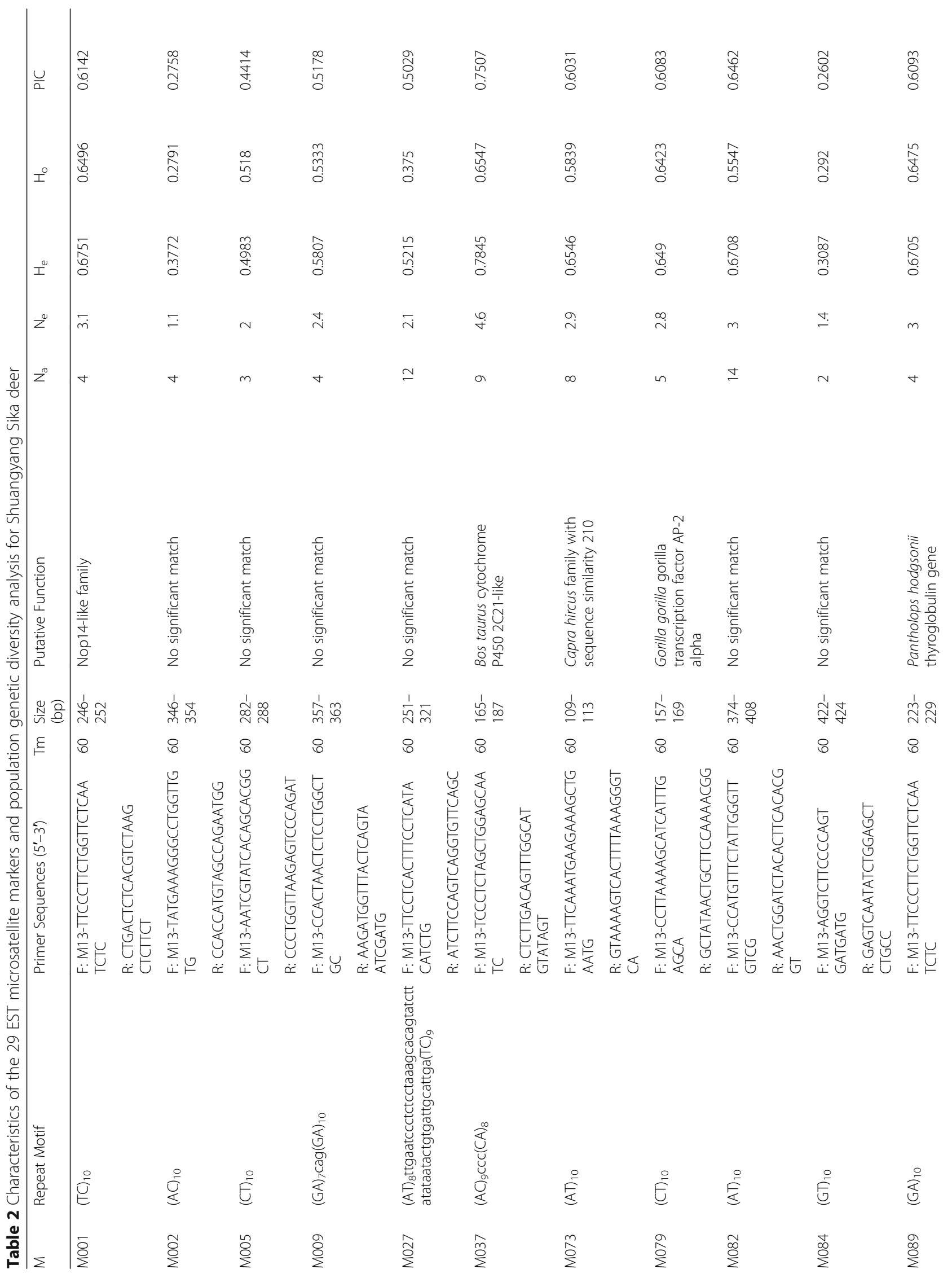




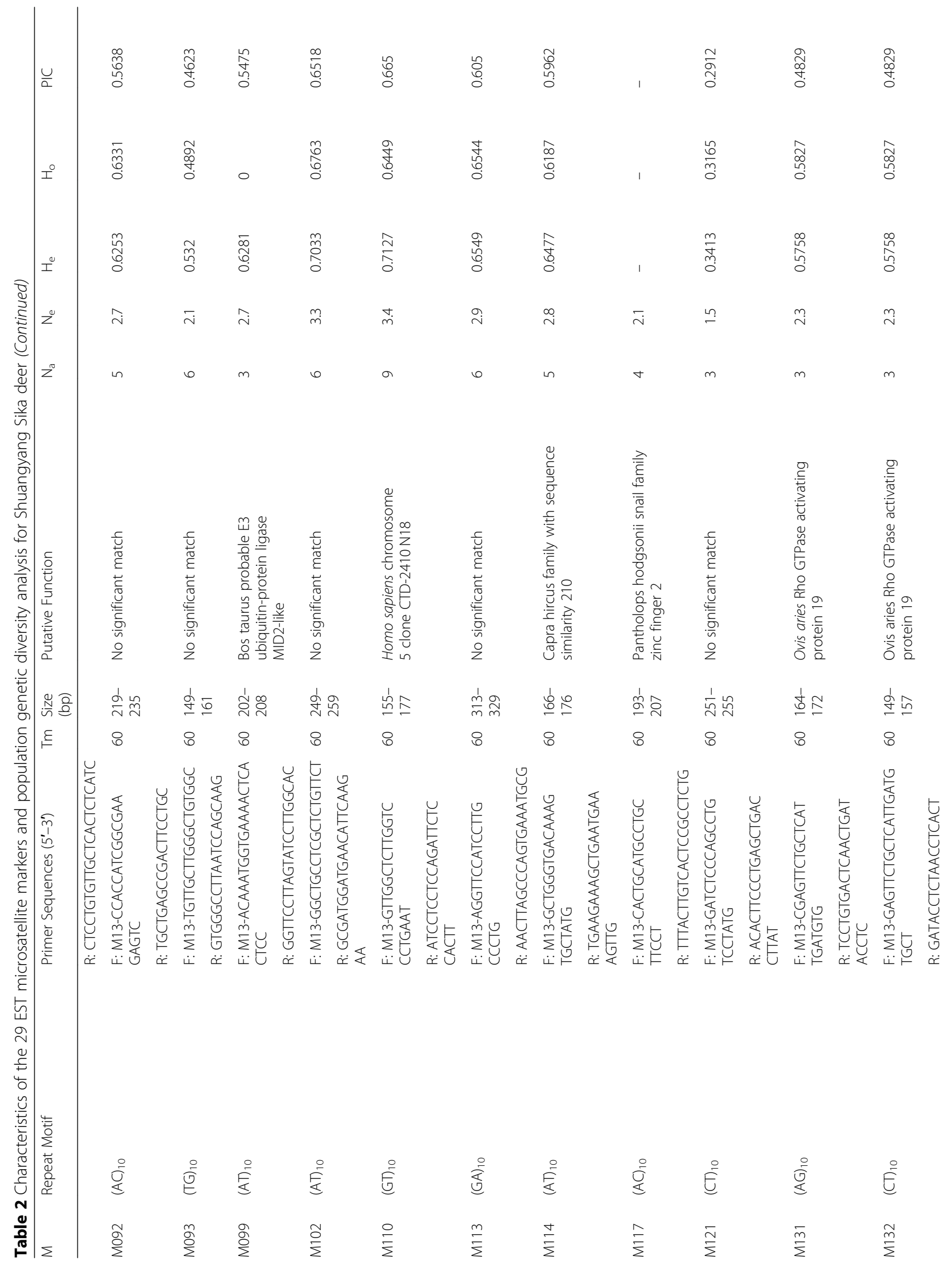




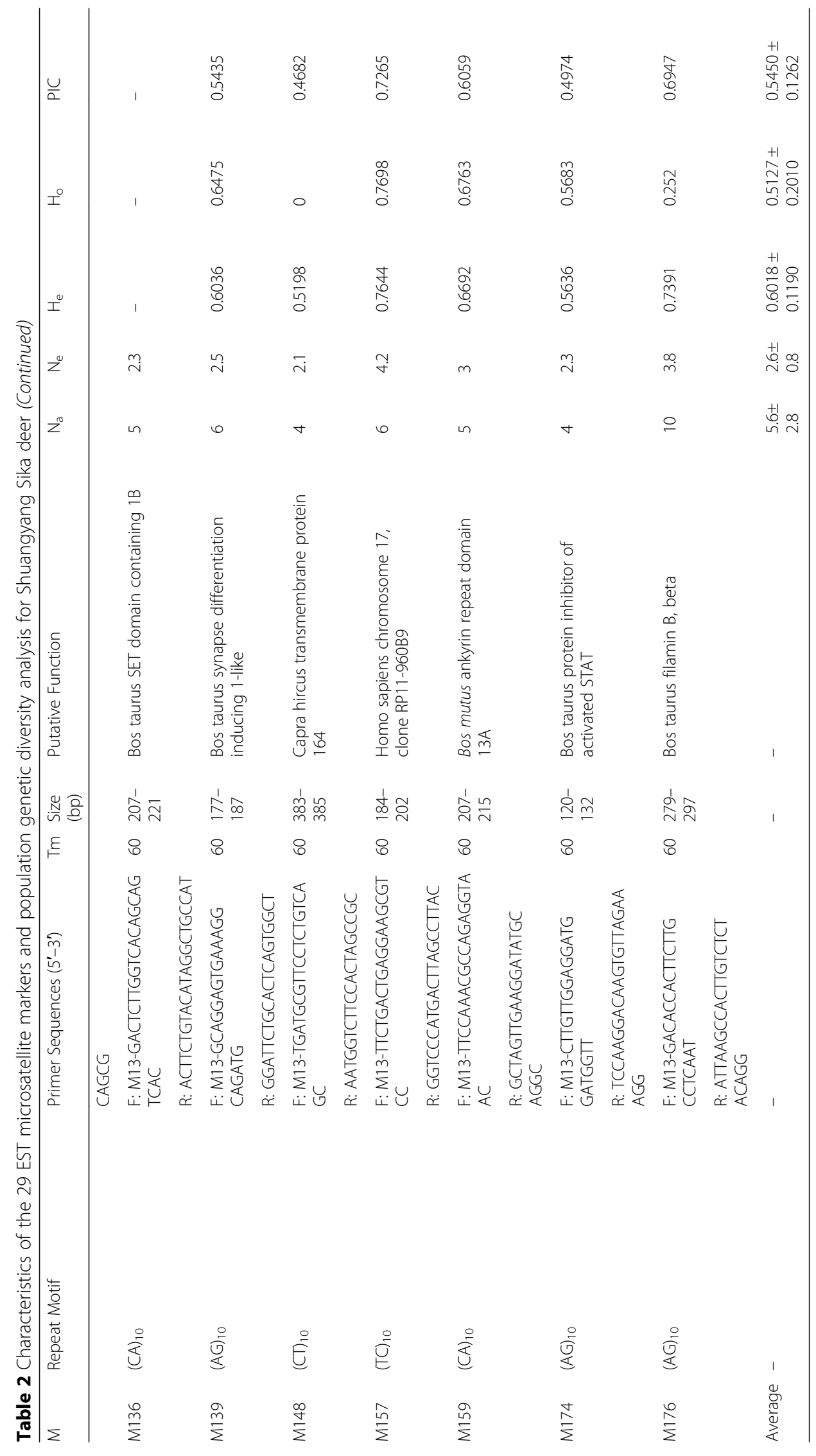


Table 3 Multiple linear regression analysis of influencing factors and velvet antler weight

\begin{tabular}{|c|c|c|c|c|c|}
\hline Independent Variable & B value & Standard error & t value & $P$ value & Model Parameters \\
\hline Constant & -1.745 & 0.094 & -18.659 & 0.000 & \multirow{6}{*}{$\begin{array}{l}R^{2}=0.874 \\
R^{2} \text { adjusted }=0.869 \\
F=6.263 \\
P=0.014\end{array}$} \\
\hline Main Beam Circle & 0.071 & 0.009 & 7.964 & 0.000 & \\
\hline Main Beam Length & 0.027 & 0.006 & 4.414 & 0.000 & \\
\hline Mouth Circle & 0.043 & 0.007 & 6.069 & 0.000 & \\
\hline Mouth Length & 0.016 & 0.007 & 2.503 & 0.014 & \\
\hline First Tine Circle & 0.019 & 0.007 & 2.753 & 0.007 & \\
\hline
\end{tabular}

antler weight and main beam circle. However, the contribution of locus 289 that we concerned was not significant. On the contrary, locus 263 and 279 had the lowest mean value of velvet antler weight and main beam circle (Table 8). Combined with other genotype individuals, it could be speculated that the locus 321 of genotype 289/ 321 had a positive effect, while the locus 263 of genotype $263 / 263$ had a negative impact on velvet antler weight and main beam circle of two-branched velvet antler of shuangyang Sika deer.

\section{Discussion}

EST microsatellite were powerful molecular markers for analyzing population genetic diversity, molecular breeding and functions [27]. However, to date, few studies about EST microsatellite markers had been reported from Sika deer. Development of EST microsatellite markers based on transcriptome data was still an economic and efficient development strategy of DNA molecular markers. Our study was the first attempt to obtain transcriptional information of Sika deer for the EST microsatellite and to further examine the diversity and velvet antler yield characters. We successfully and efficiently isolated 182,295 EST microsatellite markers by IlluminaHiSeq ${ }^{\mathrm{Tm}} 2500$ sequencing technology. So far,

Table 4 Correlation analysis between microsatellite loci polymorphism and velvet antler traits of Sika deer

\begin{tabular}{llll}
\hline Velvet Antler Trait & EST microsatellite & P-Value & $R^{2}$ \\
\hline Velvet Antler Weight & M009 & 0.0403 & 0.147849 \\
Velvet Antler Weight & M027 & 0.002742 & 0.338763 \\
Main Beam Length & M009 & 0.021365 & 0.163189 \\
Main Beam length & M084 & 0.008272 & 0.087284 \\
Main Beam Length & M159 & 0.030037 & 0.165064 \\
Main Beam Circle & M027 & 0.004684 & 0.326376 \\
Main Beam Circle & M093 & 0.013715 & 0.183563 \\
Mouth Length & M084 & 0.017309 & 0.074358 \\
Mouth Circle & M001 & 0.031749 & 0.152333 \\
Mouth Circle & M027 & 0.001891 & 0.347053 \\
Mouth Circle & M113 & 0.004284 & 0.252471 \\
Mouth Circle & M136 & 0.000159 & 0.272411 \\
\hline Bonferroni correction for multiple testing was applied to the $P$-value &
\end{tabular}

we have obtained the largest number of Sika deer microsatellite databases to facilitate future research. The distribution of EST microsatellites with $1-6$ bp repeat motif showed that, mono-nucleotide is the most abundant motif type, followed by di-nucleotide, tri-nucleotide, tetra-nucleotide, penta-nucleotide and hexa-nucleotide repeats. This was similar to the previous study on the development of microsatellites by reducedrepresentation genome sequencing in Sika deer [21]. The difference was that the number of microsatellites obtained by transcriptome sequencing was far more than that obtained by genome sequencing. However, the number of microsatellites highly repetitive motifs $(\geq 10)$ from tri-nucleotide to hexa-nucleotide obtained by genome sequencing was more than that obtained by transcriptome sequencing. In this study, both mononucleotide and di-nucleotide repeats have been found to be the predominant repeat types. A/T, AC/GT, AGC/ CTG were the most abundant repeat among mono, di and tri-nucleotide types, which were similar to previous studies by reduced-representation genome sequencing [21]. However, AATG/ATTC was the most frequent repeat among tetra-nucleotide types, unlike AAAC previously reported in Sika deer [21]. Thus, the EST microsatellite types obtained by transcriptome sequencing and reduced-representation genome sequencing without reference genomes were different. The microsatellite loci obtained from transcriptome showed lower polymorphism compared with genome but were more likely to be related to functional loci.

As we all know, Shuangyang Sika deer was the first breed that had been identified by the state in China. It had excellent traits such as high yield, strong adaptability, early maturity and so on. Among all the breeds, the breeding scale and social benefits of Shuangyang Sika deer were the largest. In order to further study the genetics of Shuangyang Sika deer and to screen microsatellites related to velvet antler growth characteristics, 29 highly polymorphic EST microsatellites were developed from 170 microsatellites expressed in velvet antler, which showed that transcriptome sequencing technology could be used to efficiently develop microsatellites. The indicators reflecting the genetic diversity of the population mainly include $\mathrm{He}, \mathrm{Ho}, \mathrm{PIC}, \mathrm{Ne}$ and so on. Firstly, 


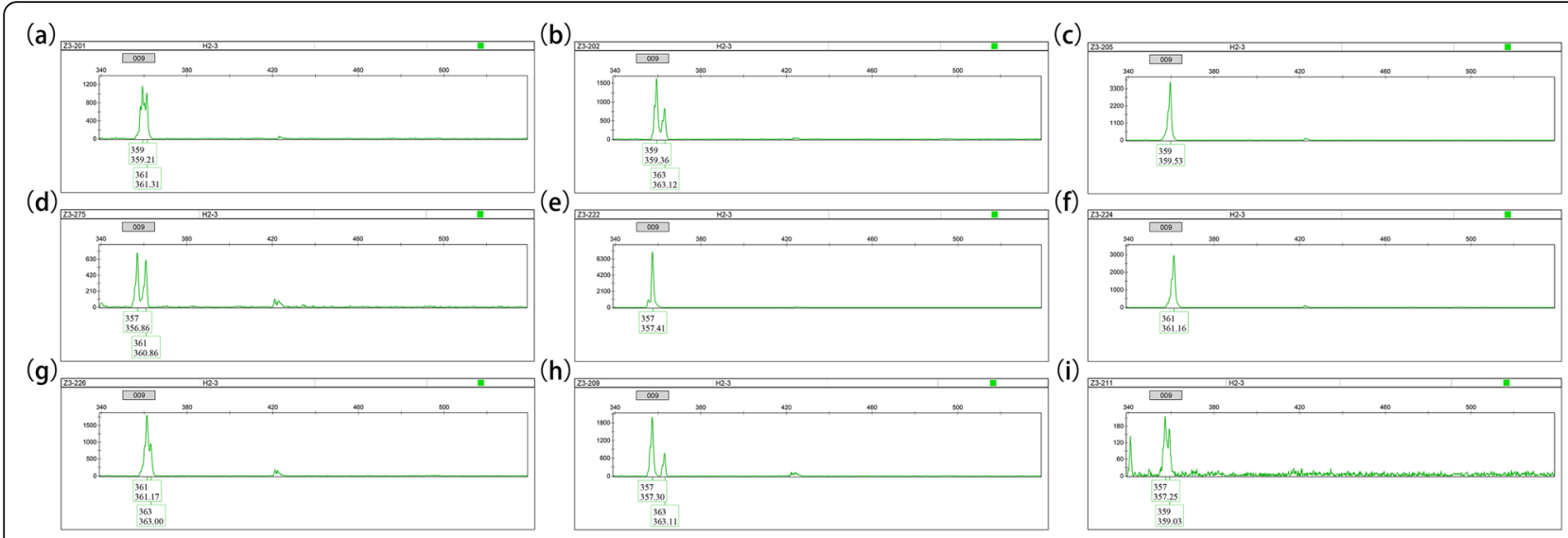

Fig. 2 Typical fluorescence signals of the M009 microsatellite loci by capillary electrophoresis fragment analysis. The numbers above the sharp peaks represent length scales based on the internal size standard (bp). The numbers below the sharp peaks represent fragment lengths of PCR amplifications (bp). a 359/361, b 359/363, c 359/359, d 357/361, e 357/357, f 361/361, g 361/363, h 357/363, i 357/359

the Ho $(\mathrm{Ho}=0.5127)$ of 29 loci developed from Shuangyang Sika deer was lower than $\mathrm{He}(\mathrm{He}=0.6018)$. The result showed that there was a certain degree of inbreeding in the Shuangyang Sika deer population, which was supposed to be caused by geographical isolation. Secondly, compared with previous studies, the PIC values of Shuangyang Sika deer $(\mathrm{PIC}=0.545)$ was lower than Linyi Sika deer $(\mathrm{PIC}=0.662)$, Yangzhou Sika deer $\quad(\mathrm{PIC}=$ 0.570 ) and Jilin Sika deer $(\mathrm{PIC}=0.680$, Shuangyang was a city in Jilin Province). The result was mainly due to the relatively conservative coding region, the polymorphism of the EST microsatellite derived from the transcriptome was lower than that of the G microsatellite derived from the genome. Then it was caused by the difference in geographical location and breeding degree. Finally, the $\mathrm{Na}$ of some EST microsatellites, such as M027 $(\mathrm{Na}=$ $12, \mathrm{Ne}=2.1), \operatorname{M082}(\mathrm{Na}=14, \mathrm{Ne}=3.0)$ and $\mathrm{M} 176(\mathrm{Na}=$ $10, \mathrm{Ne}=3.8$ ), was much larger than the Ne. However,

Table 5 Correlation analysis between M009 and velvet antler traits of Sika deer

\begin{tabular}{lll}
\hline M009 & Velvet Antler Weight $(\mathrm{kg})$ & Main Beam Length $(\mathrm{cm})$ \\
\hline $357: 363$ & $1.379 \pm 0.028^{\mathrm{a}}$ & $28.000 \pm 0.583^{\mathrm{a}}$ \\
$359: 363$ & $1.049 \pm 0.033^{\mathrm{ab}}$ & $22.803 \pm 0.760^{\mathrm{ab}}$ \\
$357: 359$ & $0.991 \pm 0.041^{\mathrm{ab}}$ & $21.026 \pm 0.956^{\mathrm{b}}$ \\
$359: 359$ & $0.866 \pm 0.027^{\mathrm{ab}}$ & $20.543 \pm 0.708^{\mathrm{b}}$ \\
$361: 363$ & $0.848 \pm 0.045^{\mathrm{ab}}$ & $20.825 \pm 1.225^{\mathrm{b}}$ \\
$357: 357$ & $0.828 \pm 0.041^{\mathrm{ab}}$ & $21.333 \pm 1.185^{\mathrm{b}}$ \\
$359: 361$ & $0.818 \pm 0.045^{\mathrm{ab}}$ & $21.500 \pm 1.344^{\mathrm{b}}$ \\
$357: 361$ & $0.784 \pm 0.034^{\mathrm{ab}}$ & $24.000 \pm 1.143^{\mathrm{ab}}$ \\
$361: 361$ & $0.523 \pm 0.015^{\mathrm{b}}$ & $15.954 \pm 0.469^{\mathrm{b}}$
\end{tabular}

In the same column, those with the same letters indicate that there was no significant difference between the two genotypes and those with different letters indicate that there was significant difference between the two genotypes the average $\mathrm{Na}$ of $29 \mathrm{EST}$ microsatellites was close to $\mathrm{Ne}$ $(\mathrm{Na}=5.6, \mathrm{Ne}=2.6)$. This indicated that some of the microsatellite alleles were unevenly distributed in the population, but the overall distribution remains uniform. The reason for this phenomenon may be that during the long-term breeding process of Shuangyang Sika deer, some loci were subject to strong selection pressures associated with velvet antler growth characteristics, resulting in uneven distribution of alleles.

Multiple linear regression analysis identified that velvet antler weight was positively correlated with main beam circle, main beam length, mouth circle, mouth length, first tine circle. Main beam circle, main beam length, mouth circle, mouth length and first tine circle have the potential to predict $86.9 \%$ of the variability of velvet antler weight. Surprisingly, there was no linear relationship between first tine length and velvet antler weight. Therefore, the data of first tine length have not been further analyzed. One of most important implications of this study was that 8 EST microsatellites were found can be used in correlation analysis of velvet antler growth characteristics. In particular, M009 and M027 can be used as molecular markers in the breeding process of weight of the two-branched velvet antler. Velvet antler weight was very important for the production performance of Chinese Sika deer [28]. Therefore, it was necessary to develop large-scale molecular markers associated with velvet antler weight by sequencing. Hu et al. (2019) found that 94 SNP genetic variations were related to the threebranched velvet antler weight [28]. There were two significant differences between our study and that of $\mathrm{Hu}$ et al. (2019). First, Hu et al. (2019) chose the threebranched velvet antler (growth period of 75 days) as the research object, while we chose the two-branched velvet antler (growth period of 45 days) as the research object. Compared with the three-branched velvet antler, the 

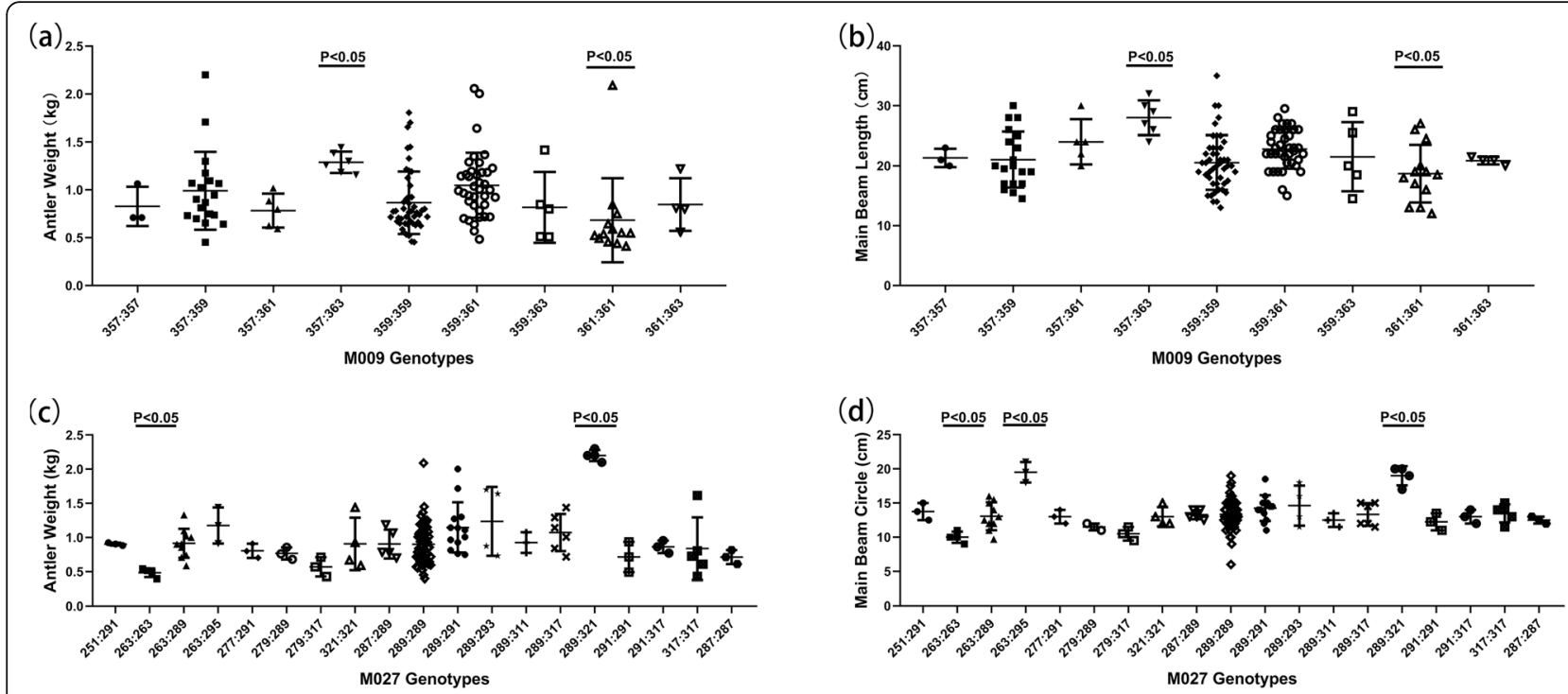

Fig. 3 Correlation analysis between microsatellites and velvet antler traits of Sika deer. a Correlation analysis between M009 genotypes and velvet antler weight. b Correlation analysis between M009 genotypes and main beam length of velvet antler. c Correlation analysis between M027 genotypes and velvet antler weight. $\mathbf{d}$ Correlation analysis between M027 genotypes and main beam circle of velvet antler

two-branched velvet antler had lowered the rate of ossification, more organic components and greater medicinal value [29]. Secondly, most of the SNP sites developed by $\mathrm{Hu}$ et al. (2019) were in the intron region of the gene. However, the microsatellites we developed were in the exon region of the gene, which may obtain the concerned functional genes possibly associated with the growth and development of velvet antler. As we all know, complex characteristics could not be completely controlled by a single gene, and it required a series of genes. So far, screening weight related molecular markers of velvet antlers were still very limited. Molecular markers must be developed by using highthroughput omics data. In this study, microsatellite databases of Sika deer were developed by using transcriptome sequences. We investigated candidate EST microsatellite related to the characteristics in twobranched velvet antler. The result would facilitate further studies breeding of Sika deer and genetic mechanism of velvet antler weight difference.

Table 6 Correlation analysis between M009 alleles and velvet antler traits of Sika deer

\begin{tabular}{lll}
\hline M009 Alleles & Velvet Antler Weight $(\mathrm{kg})$ & Main Beam Length $(\mathrm{cm})$ \\
\hline 363 & $1.073 \pm 0.031^{\mathrm{a}}$ & $23.288 \pm 0.728^{\mathrm{a}}$ \\
357 & $1.000 \pm 0.034^{\mathrm{ab}}$ & $22.653 \pm 0.839^{\mathrm{ab}}$ \\
359 & $0.924 \pm 0.020^{\mathrm{b}}$ & $21.183 \pm 0.481^{\mathrm{b}}$ \\
361 & $0.652 \pm 0.021^{\mathrm{c}}$ & $18.140 \pm 0.626^{\mathrm{c}}$
\end{tabular}

In the same column, those with the same letters indicate that there was no significant difference between the two genotypes and those with different letters indicate that there was significant difference between the two genotypes

\section{Conclusion}

In this study, we conducted a transcriptome survey of sika deer using next-generation sequencing technology. We obtained useful data of EST microsatellite, such as the frequency and distribution. Secondly, EST microsatellites were selected and further characterized for polymorphism analysis. Finally, the marker-trait association was tested for important and kernel characteristics of velvet antler in sika deer. The development of a large number of sika deer molecular markers could help to breeding and culture.

\section{Materials}

\section{Sample collection}

Twelve male Sika deer (three for each of the four developmental stages) were exsanguinated after general anesthesia. Ten types of tissue (adrenal, velvet antler, brain, heart, kidney, lung, liver, skeletal muscle, spleen and testes) from one-year-old (juvenile), 3 years old (adolescence), 5 years old (adult), and 10 years old (aged) Sika deer were then collected. Fresh samples of these tissues were immediately frozen in liquid nitrogen, and then stored at $-80^{\circ} \mathrm{C}$ for RNA extraction.

One hundred forty healthy 2-year-old male Shuangyang Sika deer were randomly selected. All Sika deer came from the commercial farm under the same living conditions (Jilin Province). The samples were blooded from jugular vein of Sika deer after general anesthesia. Anticoagulant blood was stored in $-20^{\circ} \mathrm{C}$ until DNA extraction. The price of two-branched velvet antler was higher than that of three-branched velvet antler in Asian market. It took about 45 days for velvet antler to grow 


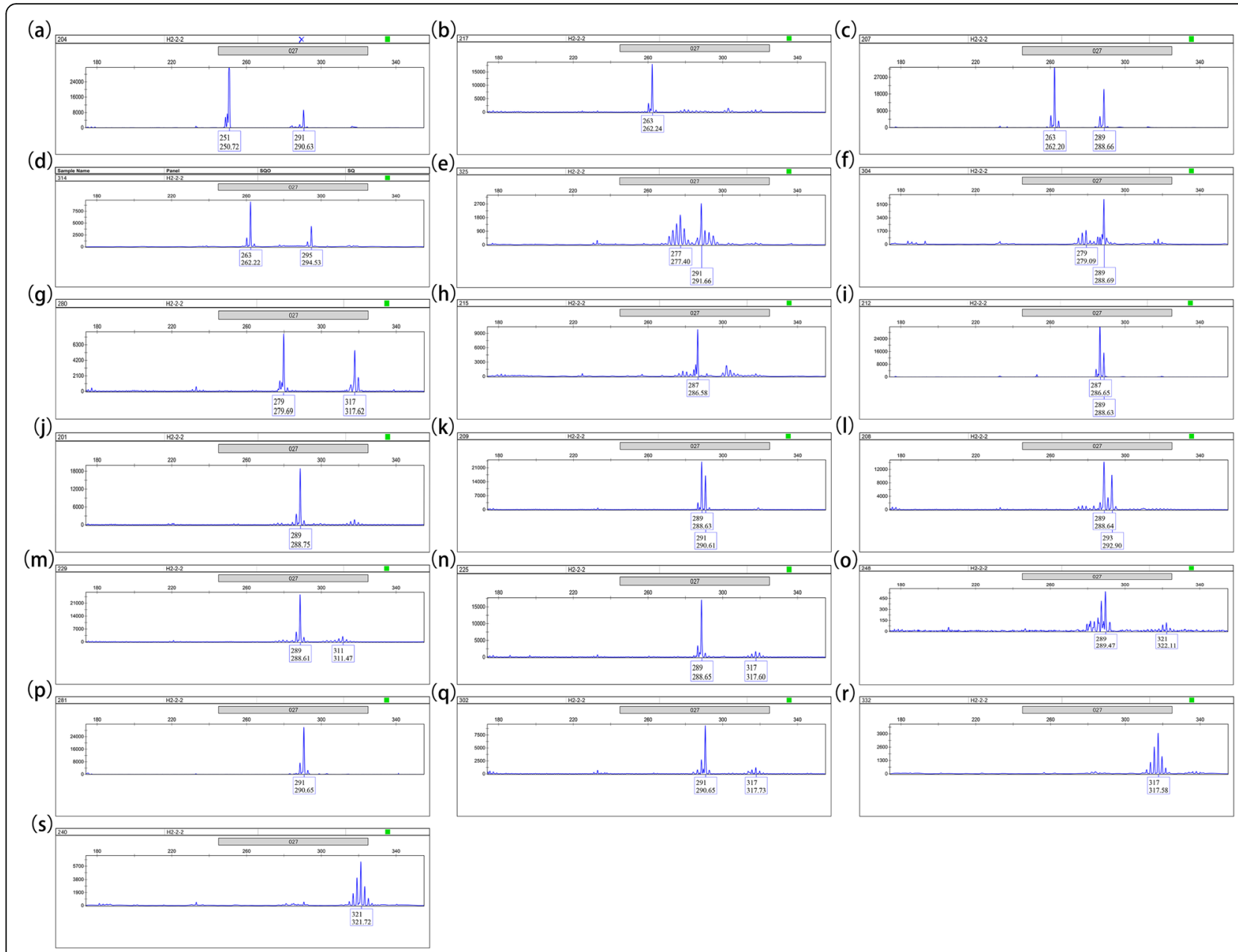

Fig. 4 Typical fluorescence signals of the M027 microsatellite loci by capillary electrophoresis fragment analysis. The numbers above the sharp peaks represent length scales based on the internal size standard (bp). The numbers below the sharp peaks represent fragment lengths of PCR amplifications (bp). a 251/291, b 263/263, c 263/289, d 263/295, e 277/291, f 279/289, g 279/317, h 287/287, i 287/289, j 289/289, k 289/291, I 289/293, m 289/311, n 289/317, o 289/321, p 291/291, q 291/317, r 317/317, s 321/321

into two-branched velvet antler. Therefore, after individual anesthesia, velvet antlers were harvested for measuring (velvet antler weight, main beam length, main beam circle, first tine length, first tine circle, mouth length, mouth circle) and sample collection at 50 days of growth.

\section{Development of EST microsatellite markers derived from transcriptome of Sika deer}

We have carried out Illumina Hiseq 2500 technology to perform high-throughput deep sequencing of the Sika deer transcriptome, with a cDNA library constructed by one RNA pool which had an equal quantity of total RNA extracted from adrenal, velvet antler, brain, heart, kidney, lung, liver, skeletal muscle, spleen and testes of Sika deer (Specific methods referred to the articles which we have published [3]. By comparing the professional software such as picard-tools and samtools, the duplicate reads were removed, and the original results were filtered. All types of microsatellite from mononucleotides to hexa-nucleotides were identified from the unigenes using MISA software under default parameter settings: a minimum of ten repeats for mono-nucleotide, six repeats for di-nucleotide microsatellites, five repeats for tri-nucleotide, tetra-nucleotide, penta-nucleotide and hexa-nucleotide microsatellites. Finally, in order to verify the identified microsatellite markers, all the microsatellites data need to be further screened. Polymorphism was one of the important criteria for judging the usability of microsatellite markers. The length of microsatellite fragment was one of the important factors which affecting its polymorphism. The polymorphism was high when the length of microsatellite was more than $20 \mathrm{bp}$, medium when the length of microsatellite was between 12 and $20 \mathrm{bp}$, and very low when the length of microsatellite was less than $12 \mathrm{bp}$ [30]. Therefore, in this study, 
Table 7 Correlation analysis between M027 and velvet antler traits of Sika deer

\begin{tabular}{|c|c|c|}
\hline M027 & Velvet Antler Weight (kg) & Main Beam Circle $(\mathrm{cm})$ \\
\hline $289: 321$ & $2.200 \pm 0.041^{a}$ & $19.000 \pm 0.345^{a}$ \\
\hline 289:293 & $1.237 \pm 0.063^{b}$ & $14.667 \pm 0.772^{b}$ \\
\hline $263: 295$ & $1.176 \pm 0.045^{b c}$ & $19.500 \pm 0.813^{a}$ \\
\hline $289: 291$ & $1.147 \pm 0.038^{b c}$ & $14.273 \pm 0.492^{b c}$ \\
\hline $289: 317$ & $1.073 \pm 0.037^{b c}$ & $13.375 \pm 0.495^{\mathrm{bcd}}$ \\
\hline 289:311 & $0.926 \pm 0.032^{b c}$ & $12.500 \pm 0.446^{b c d}$ \\
\hline $263: 289$ & $0.915 \pm 0.027^{b c}$ & $13.071 \pm 0.396^{\mathrm{bcd}}$ \\
\hline $321: 321$ & $0.906 \pm 0.048^{b c}$ & $13.000 \pm 0.722^{\mathrm{bcd}}$ \\
\hline $287: 289$ & $0.904 \pm 0.032^{b c}$ & $13.300 \pm 0.512^{\mathrm{bcd}}$ \\
\hline $251: 291$ & $0.903 \pm 0.019^{b c}$ & $13.750 \pm 0.275^{\mathrm{bcd}}$ \\
\hline $289: 289$ & $0.883 \pm 0.021^{b c}$ & $13.333 \pm 0.267^{\mathrm{bcd}}$ \\
\hline 291:317 & $0.864 \pm 0.024^{b c}$ & $13.000 \pm 0.351^{\mathrm{bcd}}$ \\
\hline $317: 317$ & $0.838 \pm 0.047^{b c}$ & $13.500 \pm 0.794^{\mathrm{bcd}}$ \\
\hline 277:291 & $0.805 \pm 0.024^{b c}$ & $13.000 \pm 0.394^{\mathrm{bcd}}$ \\
\hline $279: 289$ & $0.767 \pm 0.022^{b c}$ & $11.500 \pm 0.338^{\mathrm{bcd}}$ \\
\hline 291:291 & $0.715 \pm 0.034^{b c}$ & $12.250 \pm 0.613^{b c d}$ \\
\hline $287: 287$ & $0.714 \pm 0.022^{b c}$ & $12.500 \pm 0.403^{b c d}$ \\
\hline 279:317 & $0.570 \pm 0.024^{b c}$ & $10.500 \pm 0.457^{\mathrm{cd}}$ \\
\hline $263: 263$ & $0.485 \pm 0.014^{c}$ & $10.000 \pm 0.294^{d}$ \\
\hline
\end{tabular}

In the same column, those with the same letters indicate that there was no significant difference between the two genotypes and those with different letters indicate that there was significant difference between the two genotypes

Table 8 Correlation analysis between M027 alleles and velvet antler traits of Sika deer

\begin{tabular}{lll}
\hline M027 Alleles & Velvet Antler Weight $(\mathrm{kg})$ & Main Beam Circle $(\mathrm{cm})$ \\
\hline 321 & $1.338 \pm 0.065^{\mathrm{a}}$ & $15.000 \pm 0.789^{\mathrm{a}}$ \\
293 & $1.237 \pm 0.069^{\mathrm{ab}}$ & $14.625 \pm 0.860^{\mathrm{ab}}$ \\
295 & $1.176 \pm 0.054^{\mathrm{abc}}$ & $19.500 \pm 0.951^{\mathrm{c}}$ \\
289 & $0.966 \pm 0.022^{\mathrm{bc}}$ & $13.520 \pm 0.314^{\mathrm{bd}}$ \\
291 & $0.962 \pm 0.032^{\mathrm{bc}}$ & $13.509 \pm 0.466^{\mathrm{bd}}$ \\
311 & $0.926 \pm 0.039^{\mathrm{bc}}$ & $12.500 \pm 0.532^{\mathrm{bd}}$ \\
251 & $0.903 \pm 0.023^{\mathrm{bc}}$ & $13.750 \pm 0.335^{\mathrm{bd}}$ \\
317 & $0.869 \pm 0.034^{\mathrm{bc}}$ & $12.977 \pm 0.540^{\mathrm{bd}}$ \\
277 & $0.805 \pm 0.029^{\mathrm{bc}}$ & $13.000 \pm 0.491^{\mathrm{bd}}$ \\
287 & $0.800 \pm 0.028^{\mathrm{c}}$ & $12.864 \pm 0.463^{\mathrm{bd}}$ \\
263 & $0.789 \pm 0.031^{\mathrm{d}}$ & $12.819 \pm 0.534^{\mathrm{bd}}$ \\
279 & $0.669 \pm 0.028^{\mathrm{d}}$ & $11.000 \pm 0.478^{\mathrm{e}}$
\end{tabular}

In the same column, those with the same letters indicate that there was no significant difference between the two genotypes and those with different letters indicate that there was significant difference between the two genotypes the length of less than $12 \mathrm{bp}$ microsatellite was removed. Among the mono-nucleotide motifs, the most common motif was $\mathrm{A} / \mathrm{T}$. It should be noted that mono-nucleotide duplication was prone to mismatches, leading to sequencing failure, so this study was not an option. A total of 200 EST microsatellites expressed in velvet antler were selected as candidate molecular markers.

\section{EST microsatellites primer pair design}

In this study, TP-M13- microsatellite PCR method was used to screen for primer [31]. Three primers were designed for PCR amplification: the first primer was $\mathrm{F}+$ M13, i.e. the 5'end of the EST microsatellite forward primer and M13 (5'-TGTAAAACGACGCCAGT-3') to be linked together. The second primer was the EST microsatellite reverse primer, and the third primer was M13 primer fluorescently labeled at the 5 'end with Cy5.

\section{DNA extraction, EST microsatellite markers validation and polymorphism examination}

The total blood genomic DNA was extracted from 140 Sika deer following the traditional proteinase $\mathrm{K}$ and phenol-chloroform extraction method and verified by electrophoresis on $1 \%$ agarose gel. DNA was stored at $20^{\circ} \mathrm{C}$ until used for PCR amplification.

Fluorescence PCR amplification was carried out in a $20 \mu \mathrm{L}$ volume containing $8 \mu \mathrm{L} 10 \times$ Buffer I, $0.4 \mu \mathrm{L}$ TP -M13(5 M), $2 \mu \mathrm{L}$ specific primer(5 M), $0.2 \mu \mathrm{L}$ Taq DNA Polymerase, $2 \mu \mathrm{L}$ DNA, $7.6 \mu \mathrm{L} \mathrm{ddH}_{2} \mathrm{O}$. Taq DNA Polymerase was purchased from Takara Co.,Ltd. The primers were synthesized from Beijing Microread Genetics Co., Ltd. The PCR program consisted of an initial step of $95^{\circ} \mathrm{C}$ for $5 \mathrm{~min}$, followed by 30 cycles of $94^{\circ} \mathrm{C}$ for $30 \mathrm{~s}$, $56^{\circ} \mathrm{C}$ for $45 \mathrm{~s}$, and $72{ }^{\circ} \mathrm{C}$ for $45 \mathrm{~s}$, followed by 10 cycles of $94{ }^{\circ} \mathrm{C}$ for $30 \mathrm{~s}, 53^{\circ} \mathrm{C}$ for $45 \mathrm{~s}, 72^{\circ} \mathrm{C}$ for $45 \mathrm{~s}$, and a final extension at $72{ }^{\circ} \mathrm{C}$ for $12 \mathrm{~min}$. The amplified products were evaluated on the ABI 3730XL DNA capillary sequencer with GeneScan 500 ROX Size Standard (Applied Biosystems, USA). The criterion for accepting a peak as polymorphic was that one peak was greater than or equal to one tenth of the other.

\section{Data analysis}

GenAlEx version 6.5 was employed for the allele data processing, which included the number of expected heterozygosity $\left(\mathrm{H}_{\mathrm{e}}\right)$, observed heterozygosity $\left(\mathrm{H}_{\mathrm{o}}\right)$, polymorphism information content (PIC), number of alleles $\left(\mathrm{N}_{\mathrm{a}}\right)$, effective number of alleles $\left(\mathrm{N}_{\mathrm{e}}\right)$ [32]. GENEPOP software was used to investigate linkage disequilibrium and to determine deviation from Hardy-Weinberg equilibrium [33]. The correlation between velvet antler weight and main beam length, main beam circle, first tine length, first tine circle, mouth length, mouth circle of velvet antler of Shuangyang Sika deer was analyzed by 
multiple linear regressions. One-way analysis of variance (one-way ANOVA)and post hoc Bonferroni tests were performed on significant analysis of EST microsatellite markers with growth characteristics (velvet antler weight, main beam length, main beam circle, first tine length, first tine circle, mouth length, mouth circle) of 140 individuals in velvet antler. A $p$ value $\leq 0.05$ was considered statistically significant difference.

\section{Supplementary information}

Supplementary information accompanies this paper at https://doi.org/10. 1186/s41065-020-00137-x.

Additional file 1. Distribution of EST microsatellite type in transcriptome of Sika deer.

\section{Abbreviations}

SNPs: Single nucleotide polymorphisms; RAPD: Random amplified polymorphic DNA; AFLPs: Amplified fragment length polymorphisms; SRAPS: Sequence-related amplified polymorphisms; EST microsatellite: Expressed sequence tag microsatellite; He: Expected heterozygosity; Ho: Observed heterozygosity; PIC: Polymorphism information content; Na: Number of alleles; Ne: Effective number of alleles

\section{Acknowledgements}

Not applicable.

\section{Authors' contributions}

Conceptualization: B.J., D.L. and F.Y.; Methodology: B.J., Y.L., Q.L., J.Z., W.Y. S.C. and J.Z.; Software: B.J., D.L. and C.G.; Writing-original draft preparation: B.J.; Writing-reviewing and editing: B.J., G.W., G.C., D.L. and F.Y.; Supervision: D.L. and F.Y. The authors read and approved the final manuscript.

\section{Funding}

This research was supported by Jilin Province Education Department Science and Technology Program during the Thirteenth Five-year Plan Period, Grant/ Award Number: JJKH20190940KJ; Scientific Research Fund Project of Jilin Agricultural University, Grant/Award Number: 201801; Science and Technology Development Plan Project of Jilin Province, Grant/Award Number: 20190301009NY; Science and Technology Development Plan projects of Jilin Province, Grant/Award Number: 20170307007YY

\section{Availability of data and materials}

All the data generated in the present research is contained in this manuscript.

\section{Ethics approval and consent to participate}

Not applicable.

\section{Consent for publication}

Not applicable.

\section{Competing interests}

The authors declare that they have no competing interests.

\section{Author details}

${ }^{1}$ College of Animal Science and Technology, Jilin Agricultural University, 2888 Xincheng Street, Changchun 130118, China. ${ }^{2}$ Institute of Wild Economic Animals and Plants and State Key Laboratory for Molecular Biology of Special Economical Animals, Chinese Academy of Agricultural Sciences, 4899 Juye Street, Changchun 130112, China. ${ }^{3}$ College of Vocational and Technical Education, Changchun Sci-Tech University, 1699 Donghua Street, Changchun 130606, China. ${ }^{4}$ Key laboratory of Straw Biology and Utilization, The Ministry of Education, Jilin Agricultural University, 2888 Xincheng Street, Changchun 130118, China. ${ }^{5}$ College of Engineering and Technology, Jilin Agricultural University, 2888 Xincheng Street, Changchun 130118, China.
Received: 7 May 2020 Accepted: 16 June 2020

Published online: 26 June 2020

\section{References}

1. Fayaz F, Aghaee Sarbarzeh M, Talebi R, Azadi A. Genetic diversity and molecular characterization of Iranian durum wheat landraces (Triticum turgidum durum (Desf.) Husn.) using DArT markers. Biochem Genet. 2019; 57(1):98-116.

2. Grover A, Sharma PC. Development and use of molecular markers: past and present. Crit Rev Biotechnol. 2016;36(2):290-302.

3. Jia BY, Ba HX, Wang GW, Yang Y, Cui XZ, Peng YH, Zheng JJ, Xing XM, Yang FH. Transcriptome analysis of sika deer in China. Mol Gen Genomics. 2016; 291(5):1941-53.

4. Lu X, Nevame Adedze YM, Chofong GN, Gandeka M, Deng Z, Teng L, Zhang X, Sun G, Si L, Li W. Identification of high-efficiency SSR markers for assessing watermelon genetic purity. J Genet. 2018;97(5):1295-306.

5. Zhou R, Wu Z, Jiang FL, Liang M. Comparison of gSSR and EST-SSR markers for analyzing genetic variability among tomato cultivars (Solanum lycopersicum L.). Genet Mol Res. 2015;14(4):13184-94.

6. Gupta PK, Rustgi S, Sharma S, Singh R, Kumar N, Balyan HS. Transferable EST-SSR markers for the study of polymorphism and genetic diversity in bread wheat. Mol Gen Genomics. 2003:270(4):315-23.

7. Varshney RK, Graner A, Sorrells ME. Genic microsatellite markers in plants: features and applications. Trends Biotechnol. 2005;23(1):48-55.

8. Guichoux E, Lagache L, Wagner S, Chaumeil P, Leger P, Lepais O, Lepoittevin C, Malausa T, Revardel E, Salin F, et al. Current trends in microsatellite genotyping. Mol Ecol Resour. 2011;11(4):591-611.

9. Zhang $Y$, Zhang $M, H u Y$, Zhuang $X, X u$ W, Li $P$, Wang Z. Mining and characterization of novel EST-SSR markers of Parrotia subaequalis (Hamamelidaceae) from the first Illumina-based transcriptome datasets. PLoS One. 2019;14(5):e0215874.

10. Yang S, Sun $X$, Jiang $X$, Wang L, Tian J, Li L, Zhao M, Zhong Q. Characterization of the Tibet plateau Jerusalem artichoke (Helianthus tuberosus L.) transcriptome by de novo assembly to discover genes associated with fructan synthesis and SSR analysis. Hereditas. 2019:156:9.

11. Liu Z, Shao W, Shen Y, Ji M, Chen W, Ye Y, Shen Y. Characterization of new microsatellite markers based on the transcriptome sequencing of Clematis finetiana. Hereditas. 2018;155:23.

12. Zhang L, Yang X, Qi X, Guo C, Jing Z. Characterizing the transcriptome and microsatellite markers for almond (Amygdalus communis L.) using the Illumina sequencing platform. Hereditas. 2018:155:14.

13. Lu T, Sun Y, Ma Q, Zhu M, Liu D, Ma J, Ma Y, Chen H, Guan W. De novo transcriptomic analysis and development of EST-SSR markers in the Siberian tiger (Panthera tigris altaica). Mol Gen Genomics. 2016;291(6):2145-57.

14. Wang J, Ge Q, Li J, Gao H, Li J, Zhao F. Identification of novel EST-SSR markers by transcriptome sequencing in ridgetail white prawn Exopalaemon carinicauda. Genes Genomics. 2018;40(2):207-15.

15. Zhang J, Ma W, Song X, Lin Q, Gui JF, Mei J. Characterization and development of EST-SSR markers derived from transcriptome of yellow catfish. Molecules. 2014;19(10):16402-15.

16. Yao B, Zhang M, Leng $X$, Zhao D. Proteomic analysis of the effects of antler extract on chondrocyte proliferation, differentiation and apoptosis. Mol Biol Rep. 2019;46(2):1635-48

17. Guo XH, Cheng XL, Liu WX, Li MH, Wei F, Ma SC. Identification of velvet antler and its mixed varieties by UPLC-QTOF-MS combined with principal component analysis. J Pharm Biomed Anal. 2019;165:18-23.

18. Ba H, Wang D, Yau TO, Shang Y, Li C. Transcriptomic analysis of different tissue layers in antler growth Center in Sika Deer (Cervus nippon). BMC Genomics. 2019;20(1):173.

19. Kruuk EB, Slate J, Pemberton JM, Brotherstone S, Guinness F, Clutton-Brock T. Antler size in red deer: heritability and selection but no evolution. Evolution. 2002:56(8):1683-95.

20. Zu Y, Pan Z, Xu Z, Yang S, Jin Y, Bai S. Status of microsatellites as genetic markers in cervids. J Forestry Res. 2001;12(1):55-8.

21. Yang W, Zheng J, Jia B, Wei H, Wang G, Yang F. Isolation of novel microsatellite markers and their application for genetic diversity and parentage analyses in sika deer. Gene. 2018:643:68-73.

22. Eva SN, Yamazaki Y. Population structure, admixture, and migration patterns of Japanese Sika deer (Cervus nippon) inhabiting Toyama prefecture in Japan. Zool Sci. 2019;36(2):128-35. 
23. Konishi S, Hata S, Matsuda S, Arai K, Mizoguchi Y. Evaluation of the genetic structure of sika deer (Cervus nippon) in Japan's Kanto and Tanzawa mountain areas, based on microsatellite markers. Anim Sci J. 2017;88(11): 1673-7.

24. Smith SL, Senn HV, Perez-Espona S, Wyman MT, Heap E, Pemberton JM. Introgression of exotic Cervus (nippon and canadensis) into red deer (Cervus elaphus) populations in Scotland and the English Lake District. Ecol Evol. 2018;8(4):2122-34.

25. Li X, Sun H, Chen B, Geng Z, Wang L. Analysis of correlation between microsatellite genetic diversity and antler weight of Xingkaihu sika deer. Chin J Anim Sci. 2011:47(9):14-7.

26. Yang F, Huo L, Yang L, Riaz H, Xiong L, Chen J, Zhang S, Xiong J. Association between melatonin receptor 1A (MTNR1A) gene singlenucleotide polymorphisms and the velvet antler yield of Sika deer. Mol Biol Rep. 2014;41(4):1901-6

27. Li Y, Korol A, Fahima T, Nevo E. Microsatellites within genes:structure, function, and evolution. Mol Biol Evol. 2004;21(6):991-1007.

28. Hu P, Wang T, Liu H, Xu J, Wang L, Zhao P, Xing X. Full-length transcriptome and microRNA sequencing reveal the specific generegulation network of velvet antler in sika deer with extremely different velvet antler weight. Mol Gen Genomics. 2019;294(2):431-43.

29. Li C, Suttie J. Morphogenetic aspects of deer antler development. Front Biosci (Elite Ed). 2012;4:1836-42.

30. Temnykh S, DeClerck G, Lukashova A, Lipovich L, Cartinhour S, McCouch S. Computational and experimental analysis of microsatellites in rice (Oryza sativa L.): frequency, length variation, transposon associations, and genetic marker potential. Genome Res. 2001;11(8):1441-52.

31. Onysk A, Boczkowska M. M13-tailed simple sequence repeat (SSR) markers in studies of genetic diversity and population structure of common oat Germplasm. Methods Mol Biol. 2017;1536:159-68.

32. Amirian A, Zafari Z, Sharifi Z, Kordafshari A, Karimipoor M, Zeinali S. Characterization and haplotype study of 6 novel STR markers related to the KCNQ1 gene in heterogeneous cardiovascular disorders in the Iranian population. Turk J Med Sci. 2019;49(2):453-7.

33. Palero F, Gonzalez-Candelas F, Pascual M. MICROSATELIGHT--pipeline to expedite microsatellite analysis. J Hered. 2011;102(2):247-9.

\section{Publisher's Note}

Springer Nature remains neutral with regard to jurisdictional claims in published maps and institutional affiliations.

Ready to submit your research? Choose BMC and benefit from:

- fast, convenient online submission

- thorough peer review by experienced researchers in your field

- rapid publication on acceptance

- support for research data, including large and complex data types

- gold Open Access which fosters wider collaboration and increased citations

- maximum visibility for your research: over $100 \mathrm{M}$ website views per year

At $\mathrm{BMC}$, research is always in progress.

Learn more biomedcentral.com/submissions 